\title{
Dysnatremias in Patients With Kidney Disease
}

\author{
Sara Combs, MD and Tomas Berl, MD \\ Division of Renal Diseases and Hypertension, University of Colorado, Aurora, CO
}

\begin{abstract}
Dysnatremias are among the most common electrolyte disorders in clinical medicine. Recent studies have shown that individuals with chronic kidney disease also are afflicted by these electrolyte disorders. Furthermore, their presence imparts an increased risk of mortality. In this review, we discuss studies in experimental animals and in humans that have attempted to establish the mechanisms responsible for limiting urinary dilution and urinary concentration in progressive kidney disease. The clinical implications of these disorders in water excretion are discussed in the setting of optimal water intake as kidney disease progresses. This review emphasizes the management of patients with chronic kidney disease who have marked abnormalities in serum sodium concentrations and gives specific recommendations for modifications in renal replacement therapy prescription in hyponatremic patients with end-stage renal disease.
\end{abstract}

\section{INDEX WORDS}

Hyponatremia; hypernatremia; chronic kidney disease; end-stage renal disease

The kidney's ability to dilute and concentrate urine is dependent on the rate of glomerular filtration. ${ }^{1}$ As kidney disease progresses, disturbances in water balance ensue, ultimately reflected in changes in serum sodium concentration. In this review, we summarize data on the prevalence and significance of hypo- and hypernatremia in chronic kidney disease (CKD) and end-stage renal disease (ESRD), analyze studies of the underlying pathophysiologic mechanisms responsible for derangements in kidney concentration and dilution, and provide an approach to the prevention and management of dysnatremias in patients with decreased kidney function.

\section{EPIDEMIOLOGY OF DYSNATREMIAS IN PATIENTS WITH KIDNEY DISEASE}

Hyponatremia is the most common electrolyte disorder, estimated to be present in 4\%-8\% of ambulatory patients and $20 \%-35 \%$ of hospitalized patients. ${ }^{2-5}$ It also is associated with increased morbidity and mortality. ${ }^{4,6,7}$ It is unclear whether hyponatremia is itself a marker of severe disease or normalization of serum sodium levels could improve patient outcomes. Hypernatremia is much less common than hyponatremia, with an estimated prevalence of $2 \%$ among patients admitted to the hospital. ${ }^{8}$ Elevated serum sodium level at admission to

Address correspondence to Tomas Berl, MD, Division of Renal Diseases and Hypertension, University of Colorado, 12700 E 19th Ave, Aurora, CO 80230. tomas.berl@ucdenver.edu. 
the intensive care unit and intensive care unit-acquired hypernatremia portend a poor prognosis ${ }^{3,5,9,10}$ but the clinical implications in less sick populations require more study.

The prevalence, incidence, and significance of dysnatremias in patients with CKD are poorly studied. Theoretically, as diluting and concentrating mechanisms become increasingly impaired with progressive disease, the prevalence and incidence of dysnatremias in patients with CKD are expected to be greater than in populations with normal kidney function. One study ${ }^{11}$ evaluated the prevalence and incidence of dysnatremias and their associated mortalities in 655,493 US veterans with non-dialysis-dependent CKD. At baseline, 13.5\% of patients had hyponatremia (serum sodium < $136 \mathrm{mEq} / \mathrm{L}$ ), and $2 \%$ had hypernatremia (serum sodium $>145 \mathrm{mEq} / \mathrm{L}$ ). During a 5.5-year median follow-up, $26 \%$ of patients had at least one episode of hyponatremia and $7 \%$ had at least one episode of hypernatremia. ${ }^{12}$ These differences in prevalence between hypo- and hypernatremia may be a function of increased thirst response in CKD. The association of serum sodium level with allcause mortality was U-shaped (Fig 1). ${ }^{13}$ After multi-variable adjustment, lower and higher serum sodium levels were associated with higher mortality, with hazard ratios of $1.93(95 \%$ confidence interval [CI], 1.83-2.03) for serum sodium level < $130 \mathrm{mEq} / \mathrm{L}, 1.28$ (95\% CI, 1.26-1.30) for $130-135.9 \mathrm{mEq} / \mathrm{L}, 1.33$ (95\% CI, 1.28-1.38) for $145.1-149.9 \mathrm{mEq} / \mathrm{L}$, and $1.56(95 \% \mathrm{CI}, 1.33-1.83)$ for $\geq 150 \mathrm{mEq} / \mathrm{L}$. The prevalence of hypernatremia, but not hyponatremia, increased in patients with more progressive kidney disease (Fig 2). ${ }^{13}$ The association between hyponatremia and mortality did not appear to vary with level of kidney function; however, the association between hypernatremia and mortality diminished with progressive kidney disease. The presence or absence of congestive heart failure, liver disease, and cancer did not alter these findings.

The association between dysnatremias and poor outcomes in patients with $\mathrm{CKD}^{11}$ is consistent with other populations. The U-shaped curve of association between mortality and dysnatremias also has been demonstrated in some intensive care unit cohorts, but hypernatremia was associated more strongly with mortality than was hyponatremia. ${ }^{3,10}$ The underlying mechanism has yet to be fully elucidated. As discussed next, findings in CKD patient populations are consistent with a physiology of impaired water handling in CKD; that is, the concentrating capacity of the kidney becomes impaired more readily than the diluting capacity, and therefore its clinical consequence, hypernatremia, has a stronger incidence association with progressive CKD than does hyponatremia. However, the prevalence of dysnatremias in CKD does not differ greatly compared with ambulatory populations without kidney disease. What remains to be studied is the underlying mechanism behind the association between mortality and dysnatremias and whether this mechanism is specific to the individual disease process.

Hyponatremia also is relatively common in patients with ESRD, and hypernatremia is rare. The prevalence of hyponatremia in one US cohort of 1,549 oligoanuric patients with ESRD on hemodialysis therapy was $29.3 \% .{ }^{14}$ In a retrospective review of peritoneal dialysis patients, the annual incidence of hyponatremia was $14.5 \% .{ }^{15}$ Although the mechanism of hyponatremia in ESRD has not been fully investigated, we presume that it most likely results from excessive interdialytic water intake. Patients with oligoanuric kidney failure cannot regulate water excretion in response to vasopressin levels and rely on sodium and water 
removal during renal replacement therapy for water and sodium homeostasis. In ESRD, hyponatremia is associated strongly with increased mortality (Fig 3), ${ }^{14,16,17}$ even when adjusted for hemodialysis modality, ultrafiltration volume, heart failure, or the presence of severe volume overload. ${ }^{14}$ The underlying mechanism for the association between mortality and hyponatremia in ESRD is unclear. Factors associated with hyponatremia in patients on peritoneal dialysis therapy demonstrated a significantly higher serum sodium level with greater residual kidney function, but lower serum sodium concentrations were associated with larger volumes of daily instilled icodextrin. ${ }^{15}$

\section{PATHOPHYSIOLOGY OF IMPAIRED CONCENTRATING AND DILUTING ABILITIES IN KIDNEY DISEASE}

\section{The Concentrating Mechanism in CKD}

In hydropenic conditions, the mammalian nephron is extremely effective in the defense of body fluid tonicity and can conserve water by excreting urine that is much more concentrated than plasma. This is a process critical to adaptation to arid terrestrial environments. A healthy young human can excrete urine with a tonicity that is approximately 4 times greater than plasma $\left(1,200 \mathrm{mOsm} / \mathrm{kg} \mathrm{H}_{2} \mathrm{O}\right)$, obligating $500 \mathrm{~mL}$ of urine per day for solute intake of $600 \mathrm{mOsm} / \mathrm{d}$. In contrast, a decrement in function causes a decrease in maximal urinary concentration. Thus, in the Lumleian Lecture in 1952, Platt ${ }^{18}$ notes, "One of the constant signs of renal failure is the inability of the kidney to produce a concentrated urine, and it is well known that the specific gravity of the urine becomes relatively fixed at 1.010, which is approximately that of blood"18(p1315); this is known as isosthenuria.

\section{Proposed Mechanisms for Impaired Urinary Concentration in CKD}

Role of Solute Excretion-Although urinary osmolality is a measure of concentrating ability, it does not provide a quantitative assessment of the capacity of the kidney to reabsorb water. This is determined better by solute-free water reabsorption $\left(\mathrm{TcH}_{2} \mathrm{O}\right)$. In the concentrating process, tubules reabsorb solute-free water from the initially isotonic glomerular filtrate. Solute-free water reabsorption is the difference between the volume of urine that would be required to excrete isotonic urine $\left(\mathrm{C}_{\mathrm{osm}}\right)$ and actual urine volume. Thus, $\mathrm{TcH}_{2} \mathrm{O}=\mathrm{C}_{\text {osm }}-\mathrm{V}$. Since $\mathrm{C}_{\text {osm }}$ is $\mathrm{U}_{\text {osm }} \mathrm{V} /$ plasma osmolality $\left(\mathrm{P}_{\text {osm }}\right), \mathrm{TcH}_{2} \mathrm{O}=\mathrm{U}_{\text {osm }} \mathrm{V} / \mathrm{P}_{\text {osm }}-$ $\mathrm{V}$. This formula also reflects the fact that $\mathrm{TcH}_{2} \mathrm{O}$ is influenced by solute excretion $\left(\mathrm{U}_{\mathrm{osm}} \mathrm{V}\right)$. When normal kidneys are exposed to increasing solute loads in the presence of supraphysiologic doses of vasopressin, maximal $\mathrm{TcH}_{2} \mathrm{O}$ can be assessed, but urinary osmolality decreases, approaching, but not falling below, plasma tonicity. ${ }^{19}$ In kidney disease, as solute intake remains constant, for the decreasing number of functioning nephrons, each must excrete an increasing fraction of the filtered solute load. Thus, remnant nephrons are subject to significant osmotic diuresis. Several investigators have undertaken studies to examine whether the limitation in ability to maximally concentrate urine can be ascribed to a functional consequence of this adaptive mechanism or a pathologic process has to be implicated in these remnant nephrons to explain the concentrating defect. Baldwin et $\mathrm{al}^{20}$ studied 25 patients and found that in most of those with mild to moderately decreased 
kidney function, water reabsorption corrected for the residual glomerular filtration rate (GFR) and $\left(\mathrm{TcH}_{2} \mathrm{O} /\right.$ inulin clearance) was equal or even higher than that observed in healthy controls, therefore suggesting normal tubular function in the remnant nephrons. A study in experimental animals supported this view. Bricker et $\mathrm{a}^{21}$ produced unilateral decrements in GFR with pyelonephritis or aminoglycoside in dogs. This allowed for a direct comparison between the affected and unaffected kidney in a nonuremic environment wherein $\mathrm{TcH}_{2} \mathrm{O}$ was measured during a mannitol diuresis independently in the 2 kidneys. $\mathrm{TcH}_{2} \mathrm{O} / \mathrm{GFR}$ was not different between the control and experimental kidneys, supporting the view that the surviving nephrons were reabsorbing water normally. Dorhout Mees, ${ }^{22,23}$ also using mannitol infusions to increase solute clearance, concluded that the decrement in $\mathrm{TcH}_{2} \mathrm{O}$ observed in 19 patients with kidney disease could not be accounted for entirely by osmotic diuresis. A similar conclusion was reached by Kleeman et al, ${ }^{24}$ who studied water balance in 27 patients with kidney disease of varying causes. When given vasopressin, these patients achieved mean urinary osmolality of $359 \mathrm{mOsm} / \mathrm{kg} \mathrm{H}_{2} \mathrm{O}$. Urinary osmolality was lower than that of healthy controls across a broad range of solute excretion, suggesting additional pathologic mechanisms directly impairing tubular function. That factors other than increased solute load per nephron must be invoked was strengthened by the observations of Tannen et al. ${ }^{25}$ These investigators found that 11 of 13 patients with advanced kidney failure, all with creatinine clearances $<15 \mathrm{~mL} / \mathrm{min}$, had urinary osmolality below that of plasma (by a mean of $17 \mathrm{mOsm} / \mathrm{kg} \mathrm{H}_{2} \mathrm{O}$ ) despite administration of maximal doses of vasopressin. Because the kidney interstitium is never hypotonic to plasma, this observation supports the view that an intrinsic disorder in the function of the collecting tubule also must be implicated. Patients who had vasopressin-resistant hyposthenuria were very advanced in their diseases.

Advanced kidney disease is associated with very high tubular flow rate and solute excretion in the few remaining functioning nephrons, thereby possibly not allowing sufficient time for the tubular fluid and its surrounding interstitium to achieve osmotic equilibrium.

Role of Medullary Interstitial Tonicity-Generation of a hypertonic interstitium is essential to the urinary concentrating process. Maintenance of the corticomedullary osmotic gradient is dependent on normal function of the thick ascending loop of Henle, where sodium chloride is reabsorbed without water and urea accumulates in the inner medulla. In a rodent model of pyelonephritis, Gilbert et $\mathrm{al}^{26}$ measured total solute content in kidney slices and found a loss of such corticomedullary gradient in diseased kidneys, but not in uninephrectomized controls. Micropuncture studies were undertaken to define the mechanism of such a loss of gradient. These studies revealed normal function of the ascending limb because fluid and sodium delivery to the early distal tubule were normal. In contrast, the content and recycling of urea were greatly diminished, accounting for the decrement in overall interstitial tonicity. This process, if it can be extrapolated to other kidney pathologies, would lower the upper limits to which urine can be concentrated in CKD. Finally, alterations in kidney blood flow whereby more is redistributed to the medulla has been observed in models of kidney disease. ${ }^{26}$ Such redistribution could wash out solutes from the medulla, thereby decreasing its tonicity.

Role for Anatomic Pathology in the Inner Medulla-The anatomic integrity of the inner medulla is required for normal urinary concentration, as demonstrated in studies of 
papillectomized rats and rats with $65 \%$ nephrectomy, achieving modest but equal decrements in inulin clearance with both models. ${ }^{27}$ While the nephrectomized rats concentrated their urine to levels not significantly different from control rats, papillectomized rats had a marked concentrating defect. Further evidence is provided by observations made in kidney diseases that affect the medulla out of proportion to a decrement in overall kidney function. Thus, in patients with sickle cell disease, ${ }^{28}$ polycystic disease, ${ }^{29}$ and medullary cystic disease, ${ }^{30}$ a concentrating defect is evident with only modest decrements in kidney function.

Role for Impaired Collecting Tubule Water Permeability-Excretion of urine hypotonic to plasma strongly suggests failure of the collecting duct to achieve water permeability in order to equilibrate with the surrounding hypertonic interstitium. Although this can occur if vasopressin levels are inadequate, there is no evidence that this is the case in CKD because levels are elevated in such patients. ${ }^{31}$ When the vasopressin response to hypertonicity was studied in 8 patients with advanced CKD, they showed increased sensitivity to its effects with a normal threshold for the hormone's release. ${ }^{12}$ The hyposthenuria was resistant to vasopressin administration, suggesting impaired response to the hormone. A possible explanation is the presence of a vasopressin inhibitor accumulating in advanced kidney disease. One patient was studied before and after undergoing hemodialysis for 1 month without reversal of the defect, ${ }^{25}$ making it unlikely that at least a dialyzable antagonist is responsible.

A uremia-independent effect is supported further by in vitro studies performed in isolated perfused cortical collecting tubules obtained from remnant kidneys of uremic rabbits bathed in either normal or uremic serum. Using the same concentration gradient, the hydro-osmotic response to vasopressin was markedly blunted in cortical collecting tubules obtained from uremic rabbits whether bathed in normal or uremic media ${ }^{32}$ (Fig 4). The cellular mechanism responsible for this blunted response was investigated. Vasopressin-stimulated adenylate cyclase activity was blunted equally in cortical collecting tubules from uremic animals. A post-cyclic adenosine monophosphate (cAMP) generation defect also was postulated because the hydraulic conductivity of these tubules failed to increase when exposed to the analogue 8-bromocyclic AMP. ${ }^{32}$ These studies were complemented by experiments in cultured inner medullary collecting tubules cells. ${ }^{33}$ Cells obtained from the inner medulla of $5 / 6$ nephrectomized rats as a model of chronic kidney failure uniquely failed to generate cAMP in response to vasopressin. The mechanism of the impaired response to vasopressin was characterized further in studies directed at its receptor. The number of receptors was decreased markedly, apparently as a consequence of decreased messenger RNA for the receptor's synthesis. ${ }^{33}$

The post-cAMP defect noted may relate to a decrease in expression of water channels in animals with reduced kidney function. Using the model of reduced kidney mass, ${ }^{34}$ rats had an increase in urine flow, decrement in maximal urinary concentration, and reduction in expression of aquaporin 1, 2, and 3 (Fig 5). ${ }^{34}$ These aquaporins are involved in the concentrating mechanism; aquaporin 1 in the descending limb of the loop of Henle and aquaporin 2 and 3 in the luminal and basolateral membranes, respectively, of principal cells of the collecting tubule. ${ }^{35}$ Because cAMP generation is involved intimately in both the 
short-term and long-term regulation of aquaporin 2 expression, these observations do not define whether the effect on water channels is secondary to blunted cAMP or a direct effect of decreased kidney function on the synthesis of these channels. A similar decrement in aquaporin 2 expression occurs after release of bilateral ureteral obstruction, another model of polyuric vasopressin-resistant concentrating defect.

Taken together, it is apparent that the inability to fully reabsorb water and thereby to maximally concentrate urine is multifactorial. Each of the mechanisms discussed can by itself or in combination with others cause the disturbance in water conservation. Some of the data are obtained in experimental animals, frequently the 5/6 nephrectomy model, and may not mimic the pathology in human disease. The severity of the defect is extremely variable and its expression may change with the nature of the underlying kidney disease.

\section{Urinary Dilution in CKD}

Some of these studies also investigated the effect of decreased kidney function on urinary dilution. Bricker et $\mathrm{al}^{21}$ studied dogs with unilateral decreased kidney function that received a 40- to $70-\mathrm{mL} / \mathrm{kg}$ intragastric water load variably given with and without isotonic sodium chloride expansion in order to increase solute clearance. Free water clearance $\left(\mathrm{CH}_{2} \mathrm{O}\right)$ was lower in the afflicted kidney than the contralateral control, but when corrected for GFR $\left(\mathrm{CH}_{2} \mathrm{O} / \mathrm{GFR} \times 100\right)$, the ratio was higher in the experimental kidney, suggesting that the remaining nephrons were diluting urine normally and the overall limitation for water excretion was related to the decrease in GFR. A defect in urinary dilution occurred later than the concentrating defect (in the course of decreased kidney function). Kleeman et $\mathrm{al}^{24}$ water loaded 27 patients with azotemia. $\mathrm{CH}_{2} \mathrm{O}$ was consistently lower in patients with kidney disease and the minimal $\mathrm{U}_{\mathrm{osm}}$ attained was $174 \mathrm{mOsm} / \mathrm{kg}$ compared to $66 \mathrm{mOsm} / \mathrm{kg}$ in controls because only one of the patients with CKD had $\mathrm{U}_{\mathrm{osm}}<100 \mathrm{mOsm} / \mathrm{kg}$. However, as with the dog studies, when $\mathrm{CH}_{2} \mathrm{O}$ was expressed per $100 \mathrm{~mL}$ of GFR, it was higher in patients with CKD. The fact that urinary osmolality can still be lowered in advanced CKD at a time when it cannot be increased with exogenous vasopressin was reported by Tannen et al. ${ }^{25}$ When 8 of their patients were given a water load, $\mathrm{U}_{\mathrm{osm}}$ decreased by $50-112 \mathrm{mOsm} / \mathrm{kg}$, although no patient attained urine with $\mathrm{U}_{\mathrm{osm}}<100 \mathrm{mOsm} / \mathrm{kg}$.

\section{CLINICAL IMPLICATIONS OF IMPAIRED WATER HOMEOSTASIS IN PATIENTS WITH CKD}

Individuals with normal urinary concentrating and diluting abilities can increase their urinary osmolality to as high as $1,200 \mathrm{mOsm} / \mathrm{kg} \mathrm{H}_{2} \mathrm{O}$ and decrease it to as low as 50 $\mathrm{mOsm} / \mathrm{kg} \mathrm{H}_{2} \mathrm{O}$. Progressive loss of kidney function is associated with a narrowing of these options (Fig 6). Thus, individuals with normal kidney function can excrete a solute load of $600 \mathrm{mOsm}$ in as little as $0.5 \mathrm{~L}$ in urine that is maximally concentrated $(600 \mathrm{mOsm} / 1,200$ $\mathrm{mOsm} / \mathrm{kg}=0.5 \mathrm{~L})$ or in dilute urine in as much as $12 \mathrm{~L}$ of urine $(600 \mathrm{mOsm} / 50 \mathrm{mOsm} / \mathrm{kg}=$ $12 \mathrm{~L})$. This allows for enormous flexibility in the volume of fluids that can be ingested without significantly perturbing serum sodium level and the tonicity of body fluids. In contrast, patients with advanced kidney failure can concentrate to only $300 \mathrm{mOsm} / \mathrm{kg}$, requiring the generation of $2 \mathrm{~L}$ of urine in order to excrete the mentioned $600 \mathrm{mOsm}$ of 
solute. Ingestion of $<2 \mathrm{~L}$ would result in progressive negative water balance and the development of hypernatremia. Likewise, if such a patient's minimal achievable urinary osmolality is $200 \mathrm{mOsm} / \mathrm{kg}$, the $600 \mathrm{mOsm}$ can be excreted in no more than $3 \mathrm{~L}$ of urine. If fluid intake is higher, the inability to further dilute urine results in water retention and the development of hyponatremia. Therefore, as kidney failure progresses, the volume of fluids that can be ingested without perturbing the tonicity of body fluids is narrowed. Assuming constant solute intake, the patient in this example can ingest $2-3 \mathrm{~L} / \mathrm{d}$, but any deviation would result in an increase or decrease in serum sodium concentration. The limitation in urinary concentration occurs earlier in the course of CKD than the inability to dilute urine. Such a defect results in the need to ingest more fluids and nocturia, a well-recognized early symptom of decreased kidney function.

\section{TREATMENT OF DYSNATREMIAS IN PATIENTS WITH CKD}

While CKD itself can lead to hyponatremia, the approach to its treatment is similar to that of patients with normal kidney function. ${ }^{36}$ This includes correction of hypovolemia, cessation of offending pharmacologic agents, treatment of underlying endocrine disorders, and attention to conditions that can concomitantly lead to hyponatremia, such as liver disease and heart failure. However, there are limitations and therapeutic interventions that need to be considered in patients with CKD, which are outlined next.

\section{Normal Saline Solution for Volume Repletion}

Normal saline solution is the treatment of choice for hypovolemic hyponatremic conditions. The limitations in water excretion shown in Fig 6 also apply to limitations in the ability to excrete sodium. The inability of patients with CKD to promptly conserve sodium in the face of volume depletion, thereby resulting in higher fractional excretion of sodium, limits the application of fractional excretion of sodium as a marker for hypovolemia. Conversely, because of the propensity of these patients to retain sodium, undesirable fluid overload can complicate treatment, calling for closer monitoring to prevent volume overload.

\section{Pharmacologic Agents That Inhibit Antidiuretic Hormone Action}

Several pharmacologic agents have been used in the treatment of euvolemic hyponatremia. Demeclocycline has been used in the treatment of syndrome of inappropriate secretion of antidiuretic hormone (SIADH) because it acts on the collecting tubule cell to diminish its responsiveness to antidiuretic hormone. However, nearly half is excreted renally and it may cause emesis, putting the patient at further risk for volume depletion. In the background of hepatic dysfunction, it can be overtly nephrotoxic. Its use therefore is not recommended in patients with decreased kidney function. Lithium, also a potent inhibitor of vasopressin action, is contraindicated in the presence of decreased kidney function because it is excreted primarily by the kidney. It can lead to blood levels that are both neuro- and nephrotoxic. Vasopressin $\mathrm{V}_{2}$ receptor antagonists have been shown to reliably increase serum sodium concentrations in a variety of clinical settings, ${ }^{37}$ but many trials have excluded enrollment of patients with moderate to severely decreased kidney function. ${ }^{37,38}$ Preliminary pharmacodynamic studies with a single oral dose of $60 \mathrm{mg}$ of tolvaptan demonstrated the generation of $\mathrm{CH}_{2} \mathrm{O}$ even in normonatremic patients with creatinine clearance of $15-30 \mathrm{~mL} /$ 
min. ${ }^{39}$ This effect appears to be delayed, but results in an increase in serum sodium level similar to that in patients with better kidney function. Vasopressin $\mathrm{V}_{2}$ receptor antagonists are likely to be less successful in patients with creatinine clearance $<15 \mathrm{~mL} / \mathrm{min}$, but some response (increased urine flow and decreased urinary osmolality) was observed in patients with advanced CKD (stages 4 and 5) and congestive heart failure. ${ }^{40}$

\section{Water Restriction}

Water restriction may be the best approach for treating hyponatremia in patients with CKD. The inability of the kidney to concentrate urine has 2 effects: it allows for a tolerable degree of water restriction, but if water restriction is too severe, it could result in an undesirable increase in serum sodium to hypernatremic levels. Thus, more frequent monitoring of serum sodium levels is required in this population than in the general population.

\section{Loop Diuretics}

In CKD, loop diuretics in higher doses can be used alone or in addition to water restriction to enhance water excretion. Many patients with decreased kidney function may be resistant to loop diuretics even at higher doses. In the scenario in which the patient is not resistant to loop diuretics, it is important to carefully monitor volume status and serum electrolyte levels on a regular basis to ensure that the patient does not become severely volume depleted, hypokalemic, or hypomagnesemic because the patient is at increased risk for volume contraction compared with patients with normal kidney function.

The development of hypernatremia in patients with CKD reflects water depletion as a consequence of failure to ingest water in the face of a concomitant inability to concentrate urine. Treatment entails restoring water losses in the form of parenteral or enteric water intake. In addition, the high rate of solute excretion per nephron and resistance to vasopressin at the collecting duct level put these patients at risk for hypernatremia because they excrete unreplaced electrolyte-free water.

\section{TREATMENT OF HYPONATREMIA IN PATIENTS WITH ESRD}

Treatment of hyponatremia in patients with ESRD primarily relies on 2 modalities: restriction of fluid intake and renal replacement therapy prescription. In the setting of longterm hemodialysis therapy, the question arises as to the best way to approach a low predialysis serum sodium level. Independent of predialysis serum sodium levels, analyses of large cohorts of hemodialysis patients have shown that a higher dialysate sodium concentration is associated with decreased mortality and hospitalizations despite higher interdialytic weight gain. ${ }^{16,17}$ In the absence of randomized prospective studies, the potential benefits need to be weighed against the risks of interdialytic weight gain and profound rapid shifts in serum sodium levels. One small study of 29 nondiabetic hemodialysis patients ${ }^{41}$ made an attempt at tailoring dialysate sodium prescription according to predialysis serum sodium levels and demonstrated that the individualized prescription decreased interdialytic weight gain, hemodialysis-related symptoms, predialysis blood pressures, and thirst, but follow-up was too short to provide conclusions about hospitalization and mortality rates. 
The most serious side effect associated with rapid correction of hyponatremia is osmotic demyelination syndrome. There has not been widespread reporting of this syndrome in the setting of hemodialysis, and high levels of brain urea may be protective against the dehydrating effects of rapid sodium correction. ${ }^{42}$ However, uremia does not provide full protection from dialysis-related osmotic demyelination syndrome because there are case studies of classic magnetic resonance imaging-proven osmotic demyelination syndrome after correction of severe hyponatremia in peritoneal and hemodialysis patients. ${ }^{43,44}$ The frequency with which chronic hyponatremia is corrected on dialysis therapy is not known, and the paucity of dialysis-related osmotic demyelination syndrome may be a consequence of a low incidence of overly rapid correction. Thrice-weekly dialysis treatments may not allow for long-term adaptive mechanisms to be operant. The risk is likely to be much higher in patients with acute kidney injury, patients initially starting on dialysis therapy, and patients with ESRD who have not been dialyzed for some time. ${ }^{45}$

When a patient who needs dialysis presents concomitantly with severe hyponatremia, determining the best dialysis regimen can pose a therapeutic dilemma. One case report of a woman who presented with acute kidney failure and serum sodium level of $112 \mathrm{mEq} / \mathrm{L}$ reported success in dialyzing her with conventional dialysis, using a dialysate sodium concentration of $130 \mathrm{mEq} / \mathrm{L}$ and limiting blood flow to $50 \mathrm{~mL} / \mathrm{min}$ for a total of 3 hours of treatment for 2 days in a row, thereafter resuming a normal hemodialysis regimen. ${ }^{46} \mathrm{Her}$ serum sodium level increased from 112 to $119 \mathrm{mEq} / \mathrm{L}$ the first day and to $123 \mathrm{mEq} / \mathrm{L}$ the subsequent day after dialysis. Another group treated a woman with acute presentation of kidney failure and hyponatremia (serum sodium, $92 \mathrm{mEq} / \mathrm{L}$ ) with continuous venovenous hemodialysis, using a blood flow rate of 100-120 mL/min, dialysate flow rate of 1,000 $\mathrm{mL} / \mathrm{h}$, and initial dialysate sodium concentration of $105 \mathrm{mEq} / \mathrm{L}$, and the dialysate sodium concentration was modified daily to maintain the sodium concentration at $6-8 \mathrm{mEq} / \mathrm{L}$ above the patient's serum sodium level. ${ }^{47}$ In the first case, there were no neurologic sequelae of osmotic demyelination syndrome, and in the second, magnetic resonance imaging of the head after treatment was free of evidence of osmotic demyelination syndrome. Both of these appear to be reasonable approaches. The general guideline for treatment should be to dialyze at lower blood flows with lower dialysate sodium levels, typically recommended to be no more than $15-20 \mathrm{mEq} / \mathrm{L}$ above the plasma sodium level. ${ }^{48,49}$ However, because with standard hemodialysis, dialysate sodium concentration cannot be decreased to $<130 \mathrm{mEq} / \mathrm{L}$, in severely hyponatremic patients (sodium $<115 \mathrm{mEq} / \mathrm{L}$ ), adjustment of blood flow and time of dialysis as described in the mentioned cases needs to be undertaken. The preferred method, we believe, in cases of severe hyponatremia (sodium $<125 \mathrm{mEq} / \mathrm{L}$ ), is continuous venovenous hemofiltration because it provides flexibility in adjustment of replacement fluid sodium (Table 1) ${ }^{50}$ and furthermore is associated with less marked changes in intracranial pressure.$^{51}$ If dialysate or replacement fluid sodium concentration cannot be adjusted, an alternative approach is the coinfusion of a hypotonic solution during the dialytic procedure.

Decreasing total-body water in hyponatremic patients with ESRD also can be performed successfully with peritoneal dialysis. Nolph et al ${ }^{52}$ demonstrated that during a hypertonic exchange with dextrose-based solutions, serum sodium concentrations increase with removal of an ultrafiltrate hyponatremic to extracellular fluid. Therefore, treatment of hyponatremia with peritoneal dialysis is performed most effectively with repeated rapid exchanges of 
hypertonic dextrose solutions to induce total-body water removal without concomitant removal of other solutes. Attention should be paid to ensure that potassium losses are prevented because they can contribute to the development and maintenance of hyponatremia in these patients. 53

\section{Acknowledgments}

Support: Dr Combs is supported by training grant 5T32DK007135-39 from National Institute of Diabetes and Digestive and Kidney Diseases.

Financial Disclosure: The authors declare that they have no relevant financial interests.

\section{References}

1. Kumar, S., Berl, T. Diseases of water metabolism. In: Schrier, RW., editor. Atlas of Diseases of the Kidney. Philadelphia, PA: Blackwell Science; 1999. p. 1.1-1.19.

2. Schrier RW, Sharma S, Shchekochikhin D. Hyponatraemia: more than just a marker of disease severity? Nat Rev Nephrol. 2013; 9(3):124.

3. Funk GC, Lindner G, Druml W, et al. Incidence and prognosis of dysnatremias present on ICU admission. Intensive Care Med. 2010; 36(2):304-311. [PubMed: 19847398]

4. Liamis G, Rodenburg EM, Hofman A, Zietse R, Stricker BH, Hoorn EJ. Electrolyte disorders in community subjects: prevalence and risk factors. Am J Med. 2013; 126(3):256-263. [PubMed: 23332973]

5. Stelfox HT, Ahmed SB, Khandwala F, Zygun D, Shahpori R, Laupland K. The epidemiology of intensive care unit-acquired hyponatraemia and hypernatraemia in medical-surgical intensive care units. Crit Care. 2008; 12(6):R162. [PubMed: 19094227]

6. Gankam-Kengne F, Ayers C, Khera A, de Lemos J, Maalouf NM. Mild hyponatremia is associated with an increased risk of death in an ambulatory setting. Kidney Int. 2013; 83(4):700-706. [PubMed: 23325088]

7. Wald R, Jaber BL, Price LL, Upadhyay A, Madias NE. Impact of hospital-associated hyponatremia on selected outcomes. Arch Intern Med. 2010; 170(3):294-302. [PubMed: 20142578]

8. Arampatzis S, Frauchiger B, Fiedler GM, et al. Characteristics, symptoms, and outcome of severe dysnatremias present on hospital admission. Am J Med. 2012; 125(11):1125 e1-1125 e7. [PubMed: 22939097]

9. Darmon M, Timsit JF, Francais A, et al. Association between hypernatraemia acquired in the ICU and mortality: a cohort study. Nephrol Dial Transplant. 2010; 25(8):2510-2515. [PubMed: 20167570]

10. Stelfox HT, Ahmed SB, Zygun D, Khandwala F, Laupland K. Characterization of intensive care unit acquired hyponatremia and hypernatremia following cardiac surgery. Can J Anaesth. 2010; 57(7):650-658. [PubMed: 20405264]

11. Kovesdy CP, Lott EH, Lu JL, et al. Hyponatremia, hypernatremia, and mortality in patients with chronic kidney disease with and without congestive heart failure. Circulation. 2012; 125(5):677684. [PubMed: 22223429]

12. Argent NB, Burrell LM, Goodship TH, Wilkinson R, Baylis PH. Osmoregulation of thirst and vasopressin release in severe chronic renal failure. Kidney Int. 1991; 39(2):295-300. [PubMed: 2002642]

13. Kovesdy CP. Significance of hypo- and hypernatremia in chronic kidney disease. Nephrol Dial Transplant. 2012; 27(3):891-898. [PubMed: 22379183]

14. Waikar SS, Curhan GC, Brunelli SM. Mortality associated with low serum sodium concentration in maintenance hemodialysis. Am J Med. 2011; 124(1):77-84. [PubMed: 21187188]

15. Dimitriadis, C., Sekercioglu, N., Pipili, C., Oreopoulos, DG., Bargman, JM. Hyponatremia in peritoneal dialysis: epidemiology in a single center and correlation with clinical and biochemical 
parameters. Perit Dial Int. [published online ahead of print May 1, 2013]http://dx.doi.org/10.3747/ pdi.2012.00085

16. Hecking M, Karaboyas A, Saran R, et al. Predialysis serum sodium level, dialysate sodium, and mortality in maintenance hemodialysis patients: the Dialysis Outcomes and Practice Patterns Study (DOPPS). Am J Kidney Dis. 2012; 59(2):238-248. [PubMed: 21944663]

17. Hecking M, Karaboyas A, Saran R, et al. Dialysate sodium concentration and the association with interdialytic weight gain, hospitalization, and mortality. Clin J Am Soc Nephrol. 2012; 7(1):92100. [PubMed: 22052942]

18. Platt R. Structural and functional adaptation in renal failure. Br Med J. 1952; 1(4772):1313-1317. [PubMed: 14935243]

19. Rapoport S, Brodsky WA, et al. Urinary flow and excretion of solutes during osmotic diuresis in hydropenic man. Am J Physiol. 1949; 156(3):433-442. [PubMed: 18121193]

20. Baldwin DS, Berman HJ, Heinemann HO, Smith HW. The elaboration of osmotically concentrated urine in renal disease. J Clin Invest. 1955; 34(6):800-807. [PubMed: 14381509]

21. Bricker NS, Dewey RR, Lubowitz H, Stokes J, Kirkensgaard T. Observations on the concentrating and diluting mechanisms of the diseased kidney. J Clin Invest. 1959; 38(3):516-523. [PubMed: 13641402]

22. Dorhout Mees EJ. Role of osmotic diuresis in impairment of concentrating ability in renal disease. Br Med J. 1959; 1(5130):1156-1158. [PubMed: 13638655]

23. Dorhout Mees EJ. Relation between maximal urine concentration, maximal water reabsorption capacity, and mannitol clearance in patients with renal disease. Br Med J. 1959; 1(5130):1159_ 1160. [PubMed: 13638656]

24. Kleeman CR, Adams DA, Maxwell MH. An evaluation of maximal water diuresis in chronic renal disease. I. Normal solute intake. J Lab Clin Med. 1961; 58:169-184. [PubMed: 13756614]

25. Tannen RL, Regal EM, Dunn MJ, Schrier RW. Vasopressin-resistant hyposthenuria in advanced chronic renal disease. N Engl J Med. 1969; 280(21):1135-1141. [PubMed: 5782121]

26. Gilbert RM, Weber H, Turchin L, Fine LG, Bourgoignie JJ, Bricker NS. A study of the intrarenal recycling of urea in the rat with chronic experimental pyelonephritis. J Clin Invest. 1976; 58(6): 1348-1357. [PubMed: 993348]

27. Finkelstein FO, Hayslett JP. Role of medullary structures in the functional adaptation of renal insufficiency. Kidney Int. 1974; 6(6):419-425. [PubMed: 4280470]

28. Hatch FE, Culbertson JW, Diggs LW. Nature of the renal concentrating defect in sickle cell disease. J Clin Invest. 1967; 46(3):336-345. [PubMed: 6023770]

29. Zittema D, Boertien WE, van Beek AP. Vasopressin, copeptin, and renal concentrating capacity in patients with autosomal dominant polycystic kidney disease without renal impairment. Clin J Am Soc Nephrol. 2012; 7(6):906-913. [PubMed: 22516290]

30. Guay-Woodford, L. Other cystic diseases. In: Floege, J.Johnson, R., Feehally, J., editors. Comprehensive Clinical Nephrology. 4. St Louis, MO: Saunders/Elsevier; 2010. p. 543-559.

31. Jawadi MH, Ho LS, Dipette D, Ross DL. Regulation of plasma arginine vasopressin in patients with chronic renal failure maintained on hemodialysis. Am J Nephrol. 1986; 6(3):175-181. [PubMed: 3740126]

32. Fine LG, Schlondorff D, Trizna W, Gilbert RM, Bricker N. Functional profile of the isolated uremic nephron. Impaired water permeability and adenylate cyclase responsiveness of the cortical collecting tubule to vasopressin. J Clin Invest. 1978; 61(6):1519-1527. [PubMed: 207738]

33. Teitelbaum I, McGuinness S. Vasopressin resistance in chronic renal failure. Evidence for the role of decreased $V_{2}$ receptor mRNA. J Clin Invest. 1995; 96(1):378-385. [PubMed: 7615808]

34. Kwon TH, Frokiaer J, Knepper MA, Nielsen S. Reduced AQP1, -2, and -3 levels in kidneys of rats with CRF induced by surgical reduction in renal mass. Am J Physiol. 1998; 275(5 pt 2):F724F741. [PubMed: 9815130]

35. Nielsen S, Agre P. The aquaporin family of water channels in kidney. Kidney Int. 1995; 48(4): 1057-1068. [PubMed: 8569067]

36. Thurman, J., Berl, T. Therapy of dysnatremic disorders. In: Wilcox, C., editor. Therapy in Nephrology and Hypertension. 3. Philadelphia, PA: Elsevier; 2008. p. 337-352. 
37. Rozen-Zvi B, Yahav D, Gheorghiade M, Korzets A, Leibovici L, Gafter U. Vasopressin receptor antagonists for the treatment of hyponatremia: systematic review and meta-analysis. Am J Kidney Dis. 2010; 56(2):325-337. [PubMed: 20538391]

38. Schrier RW, Gross P, Gheorghiade M, et al. Tolvaptan, a selective oral vasopressin $\mathrm{V}_{2}$-receptor antagonist, for hyponatremia. N Engl J Med. 2006; 355(20):2099-2112. [PubMed: 17105757]

39. Shoaf, S., Bricmont, P., Mallikaarjun, S. Pharmacokinetics and pharmacodynamics of oral tolvaptan in subjects with varying degrees of renal function. Kidney Int. [published online ahead of print September 18, 2013]http://dx.doi.org/10.1038/ki203.350

40. Otsuka, T., Sakai, Y., Ohno, D., Murasawa, T., Sato, N., Tsuruoka, S. The effects of tolvaptan on patients with severe chronic kidney disease complicated by congestive heart failure. Clin Exp Nephrol. [published online ahead of print March 13, 2013]http://dx.doi.org/10.1007/ s10157-013-0788-6

41. de Paula FM, Peixoto AJ, Pinto LV, Dorigo D, Patricio PJ, Santos SF. Clinical consequences of an individualized dialysate sodium prescription in hemodialysis patients. Kidney Int. 2004; 66(3): 1232-1238. [PubMed: 15327422]

42. Soupart A, Penninckx R, Stenuit A, Decaux G. Azotemia (48 h) decreases the risk of brain damage in rats after correction of chronic hyponatremia. Brain Res. 2000; 852(1):167-172. [PubMed: 10661508]

43. Huang WY, Weng WC, Peng TI, Ro LS, Yang CW, Chen KH. Central pontine and extrapontine myelinolysis after rapid correction of hyponatremia by hemodialysis in a uremic patient. Ren Fail. 2007; 29(5):635-638. [PubMed: 17654329]

44. Loo CS, Lim TO, Fan KS, Murad Z, Suleiman AB. Pontine myelinolysis following correction of hyponatraemia. Med J Malaysia. 1995; 50(2):180-182. [PubMed: 7565192]

45. Sirota JC, Berl T. Is osmotic demyelination a concern dialyzing hyponatremic patients? Semin Dial. 2011; 24(4):407-409. [PubMed: 21801217]

46. Wendland EM, Kaplan AA. A proposed approach to the dialysis prescription in severely hyponatremic patients with end-stage renal disease. Semin Dial. 2012; 25(1):82-85. [PubMed: 21906168]

47. Viktorsdottir O, Palsson R. Successful treatment of extreme hyponatremia in an anuric patient using continuous venovenous hemodialysis. Blood Purif. In press.

48. Daugirdas, J. Handbook of Dialysis. 4. Philadelphia, PA: Lippincott Williams \& Wilkins; 2007.

49. Sterns RH. Hemodialysis in hyponatremia: is there a risk? Semin Dial. 1990; 3:3-4.

50. Ostermann M, Dickie H, Tovey L, Treacher D. Management of sodium disorders during continuous haemofiltration. Crit Care. 2010; 14(3):418. [PubMed: 20519032]

51. Davenport A. Renal replacement therapy in the patient with acute brain injury. Am J Kidney Dis. 2001; 37(3):457-466. [PubMed: 11228168]

52. Nolph KD, Hano JE, Teschan PE. Peritoneal sodium transport during hypertonic peritoneal dialysis. Physiologic mechanisms and clinical implications. Ann Intern Med. 1969; 70(5):931941. [PubMed: 5783428]

53. Cherney DZ, Zevallos G, Oreopoulos D, Halperin ML. A physiological analysis of hyponatremia: implications for patients on peritoneal dialysis. Perit Dial Int. 2001; 21(1):7-13. [PubMed: 11280499]

\section{Biography}

Tomas Berl, MD was the David M. Hume Memorial Award recipient at the 2013 National Kidney Foundation Spring Clinical Meetings. This award was created in memory of one of the National Kidney Foundation's most distinguished members and is the highest honor given to a distinguished scientist-clinician in the field of kidney and urologic diseases. 


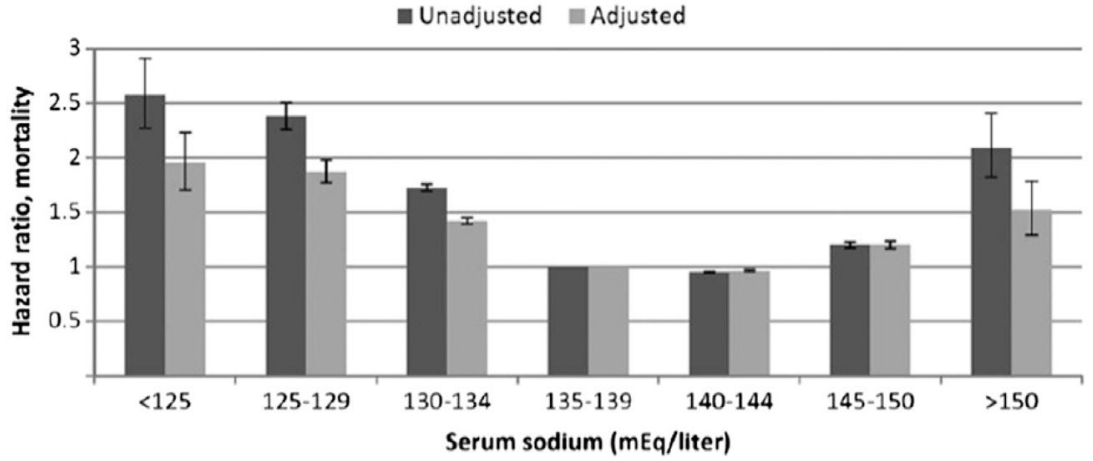

Figure 1.

Unadjusted and adjusted hazard ratios of all-cause mortality at various serum sodium levels in patients with chronic kidney disease. Reproduced from Kovesdy ${ }^{13}$ with permission of Oxford University Press. 

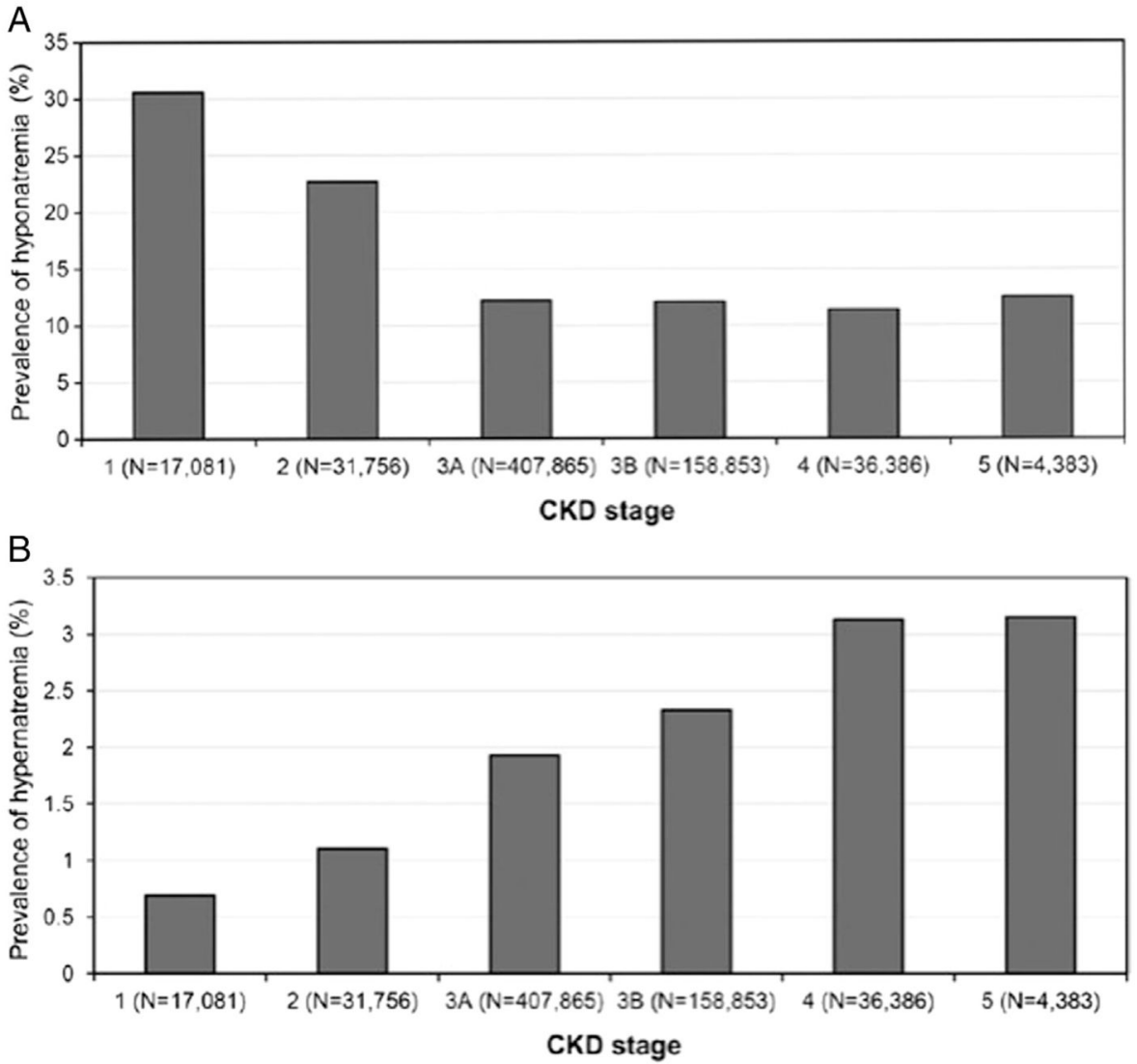

Figure 2.

Prevalences of hypo- and hypernatremia at various stages of chronic kidney disease (CKD). Note difference in scales. Reproduced from Kovesdy ${ }^{13}$ with permission of Oxford University Press. 


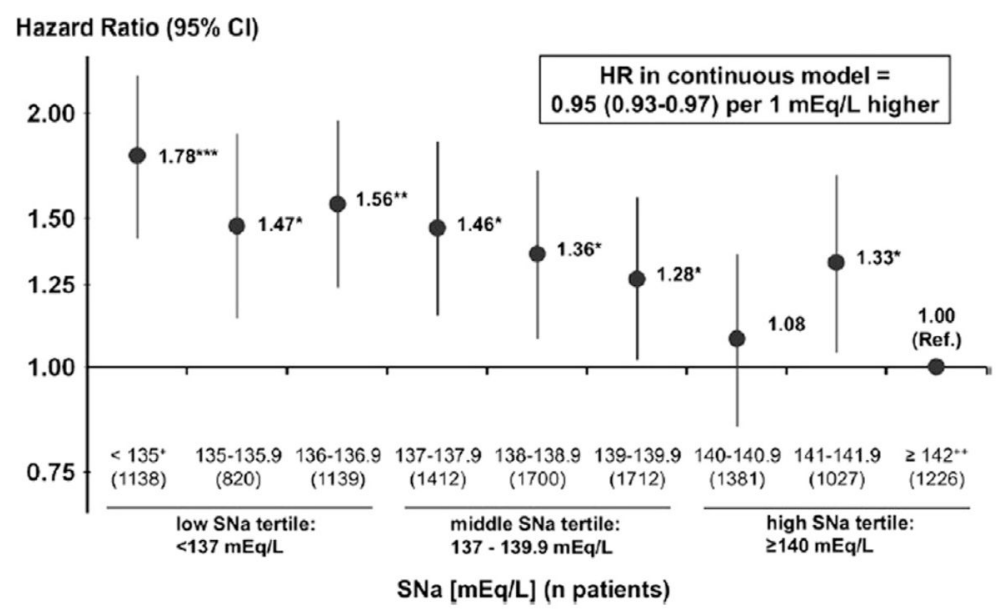

Figure 3.

Adjusted mortality risk of patients with end-stage renal disease on hemodialysis therapy associated with predialysis serum sodium (SNa) level. Abbreviations: CI, confidence interval; HR, hazard ratio. Reproduced from Hecking et al $^{16}$ with permission of Elsevier. 


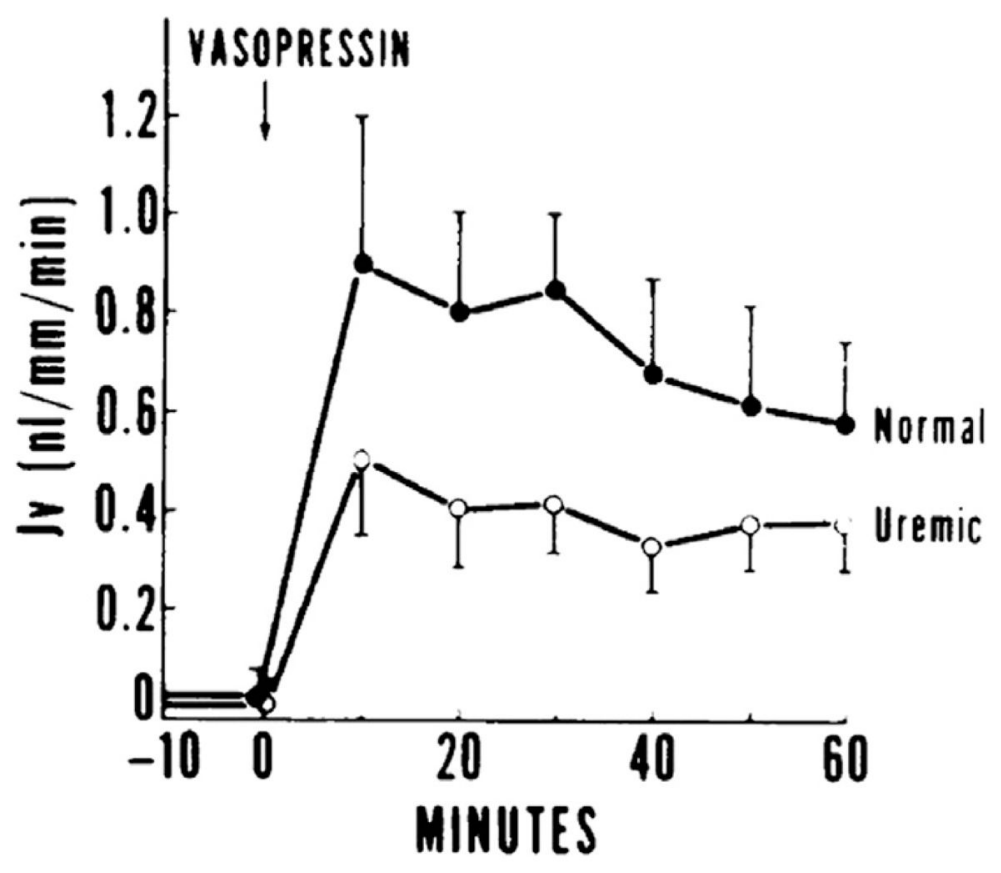

Figure 4.

Blunted hydraulic water permeability in response to vasopressin in perfused cortical collecting ducts of uremic rabbits. (Y axis label: measurement of hydraulic permeability in nanoliters per millimeter of tubule per minute). Reproduced from Fine et al ${ }^{32}$ with permission of the American Society for Clinical Investigation. 

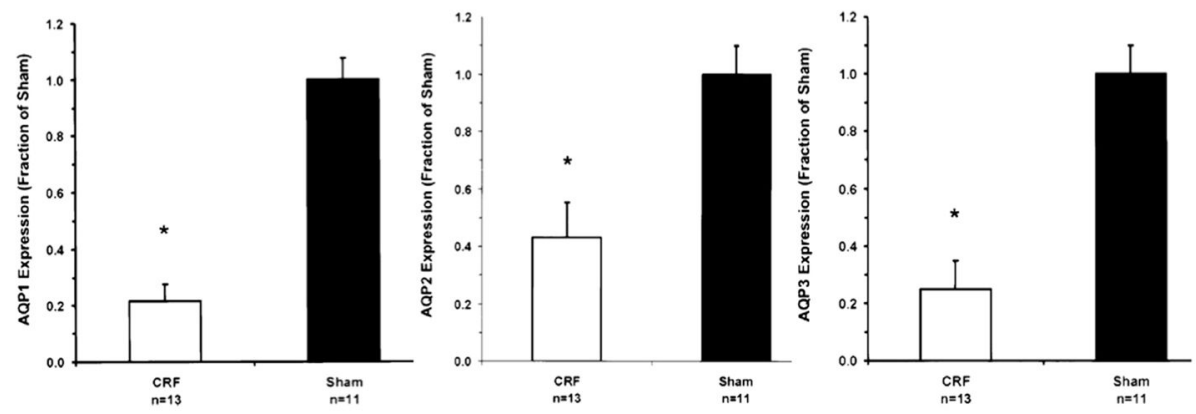

Figure 5.

Densitrometric analysis of aquaporin (AQP)1, AQP2, and AQP3 in cortical collecting ducts obtained from rats with chronic kidney disease (white bar) and their sham-operated controls (black bar). ${ }^{*} P<0.05$ for all. Abbreviation: CRF, chronic renal failure. Reproduced from Kwon et $\mathrm{al}^{34}$ with permission of the American Physiological Society. 


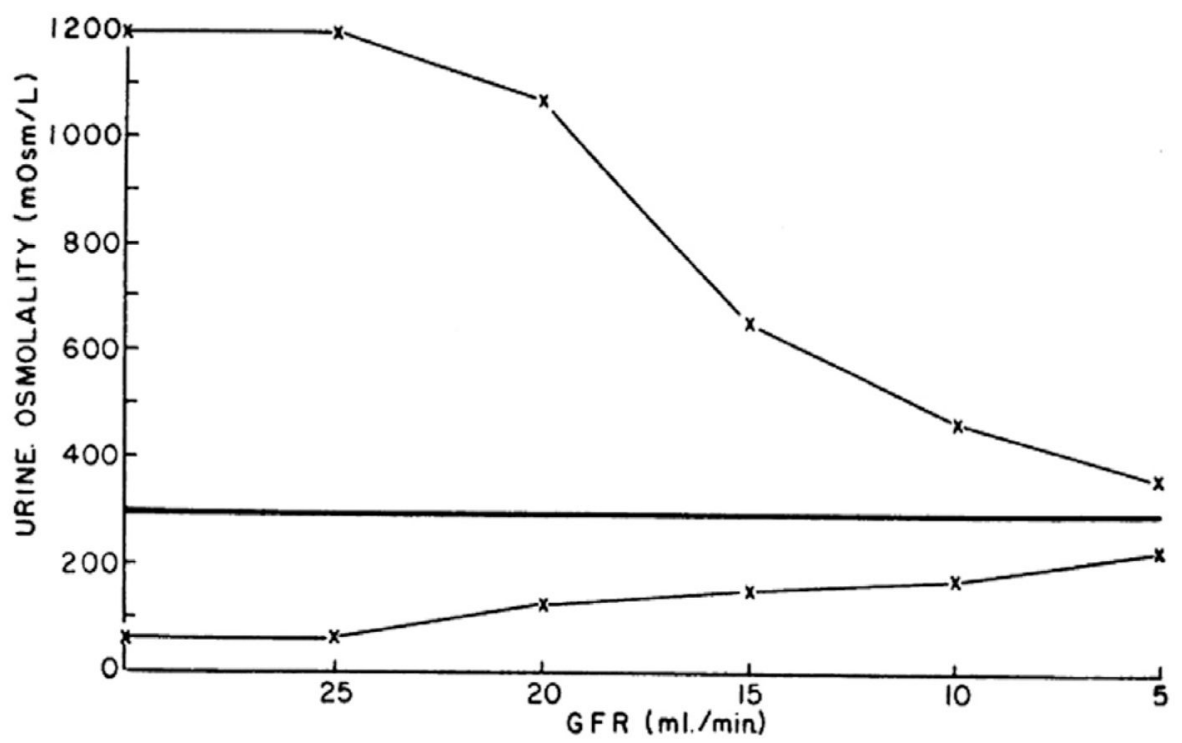

Figure 6.

Theoretical maximal and minimal urinary osmolalities in progressive kidney disease (assuming solute excretion of $600 \mathrm{mOsm} / 24 \mathrm{~h}$ ). Note the narrowing in the range of obtainable osmolalities with worsening function. Abbreviation: GFR, glomerular filtration rate. Reproduced from Bricker et $\mathrm{al}^{21}$ with permission of the American Society for Clinical Investigation. 
Table 1

Effect of Adding Different Volumes of Water to a 5-L Bag of Replacement Fluid on Its Concentrations of Sodium, Bicarbonate, and Potassium

\begin{tabular}{llccc}
\hline Volume of Water Added $(\mathbf{m L})$ & Final Volume of Diluted Fluid $(\mathbf{L})$ & {$\left[\mathbf{N a}^{+}\right](\mathbf{m E q} / \mathbf{L})$} & {$\left[\mathbf{H C O}_{3}{ }^{-}\right](\mathbf{m E q} / \mathbf{L})$} & {$\left[\mathbf{K}^{+}\right](\mathbf{m E q} / \mathbf{L})$} \\
\hline 0 & 5.0 & 140 & 35 & 4.0 \\
150 & 5.15 & 136 & 34 & 3.9 \\
250 & 5.25 & 133 & 33 & 3.8 \\
350 & 5.35 & 131 & 33 & 3.7 \\
500 & 5.5 & 127 & 32 & 3.6 \\
750 & 5.75 & 122 & 30 & 3.5 \\
1,000 & 6.0 & 117 & 29 & 3.3 \\
1,250 & 6.25 & 112 & 28 & 3.2 \\
\hline
\end{tabular}

Abbreviations: $\left[\mathrm{HCO}_{3}{ }^{-}\right]$, bicarbonate concentration; $\left[\mathrm{K}^{+}\right]$, potassium concentration; $\left[\mathrm{Na}^{+}\right]$, sodium ion concentration.

Based on data from Ostermann et al. 50 